\title{
FOREIGN STUDENT IN A RUSSIAN UNIVERSITY: TRENDS OF CHOICE, PROBLEMS OF ADAPTATION AND FORMATION OF RELATIONSHIPS
}

Chzhao Dan $^{1 *}$, Mikhail D. Rozin ${ }^{2}$, Valery P. Svechkarev ${ }^{3}$, Vladimir I. Mareev ${ }^{4}$, Yakov A. Aslanov ${ }^{5}$

${ }^{1 * 3,5}$ Institute of Sociology and Regional Studies, Southern Federal University, Rostov on Don, Russia; ${ }^{2}$ Institute of Philosophy and Socio-Political Sciences, Southern Federal University, Rostov on Don, Russia; ${ }^{4}$ Academy of Psychology and Pedagogy, Southern Federal University, Rostov on Don, Russia.

Email: ${ }^{1 *}$ zd1219@foxmail.com, ${ }^{2}$ idpr@bk.ru, ${ }^{3}$ vpsvechkarev@ sfedu.ru, ${ }^{4}$ mareev@ sfedu.ru, 5 aslanov@sfedu.ru

\section{Article History: Received on $23^{\text {rd }}$ March 2020, Revised on $24^{\text {th }}$ May 2020, Published on $21^{\text {st }}$ June 2020}

\begin{abstract}
Purpose of the study: The object of this paper is to provide a sociological analysis of the situation related to educational process and organization of foreign students in Russian universities in ratings and relationships of students from China that will help to identify the real problems of adaptation to new conditions of socio-cultural and educational space.

Methodology: The fundamental basis of this study is an observational one - an overview of the subject "Investigation of Satisfaction with the Organization of Chinese under studies' life at Russian Universities". N = 615, speaking to Chinese understudies concentrating in Russian colleges. The portrayal of sociological data is given by a multi-stage defined example with quantity determination of units of perception on the last advance.

Results: Preparing of remote understudies in China and Russia ought to completely utilize worldwide experience and training to create first-class universal seriousness, build up the status of China and Russia as nations of ground-breaking instruction on the world training market, reinforce the national security of China and Russia.

Applications of this study: In this study, the barriers to intercultural change in the field of globalization and integration of Eurasia, large educational systems such as Chinese and Russian have been identified that can be used in the globalscale analysis.

Novelty/Originality of this study: The scientific novelty of this research consists in the presentation of adaptation and intercultural transformation strategy of foreign students' educational process in Russian universities in the context of globalization and Eurasian integration of socio-cultural and educational space.
\end{abstract}

Keywords: Foreign Student Integration, Adaptation, Education Exchange, Intercultural Transformation Barriers.

\section{INTRODUCTION}

On account of understanding that China and Russia are increasingly aware of their positions as the most important strategic partners on the world stage, their cooperation is filled with new sense in all the important spheres of intergovernmental relations (economics, politics, military, etc.). Recently, special attention has been given to fuller use of "soft power" joint development opportunities, including one of the most significant - transition to a fundamentally new way of development and realization of labor (the fifth technological level), that forms cultural perspectives and dynamic development in the intellectual field. All that, of course, is about education.

Focusing on the new needs of the development of international relations in education, the government has made some significant changes in the organization of this relationships field and provided dedicated support of the entire institutional structure of Russian education system focused on attracting foreign students to study in Russian educational institutions (Zhang \& Sun, 2019). In particular, on 15 February 2005, the Ministry of Education and Science of the Russian Federation approved a decree "On Implementation of Provisions in Bologna Declaration in System of Higher Professional Education of the Russian Federation", that allowed to significantly change the attitude to a Russian diploma as to a document that fits the requirements of Bologna process, which stimulated the educational interest of foreign students to study at Russian educational institutions. On December 23, 2005, the Government of the Russian Federation has approved the documents of "Federal Target Program for the Development of Education 2006-2010", which clearly indicates that one of the major goals of the program is to increase the proportion of foreign students studying in Russian educational institutions of higher professional education on a commercial basis. All that significantly increased the export of educational services and expanded the global influence of Russian higher education. In December 2012 the Government of the Russian Federation issued a regulation "On Approval of the State Program of the Russian Federation 'Development of Education' for 2013-2020". They formulated the direction of a specific social-educational mechanism involving the formation of "differentiated network of vocational education, taking into account the regional peculiarities, including global competitive universities" by increasing "the number of Russian universities included in the first and second hundred rankings of leading world universities" (Ministry of Science and Higher Education of the Russian Federation, 2020) that contributed to the dynamic promotion of Russian higher education on the world market. In 2017 in Russia they developed and adopted the "Development of the Export Potential of the Russian Education System" project that creates "... favorable conditions for the stay of foreign citizens during their training on the territory of the Russian Federation" (Ministry of Science and Higher Education of the Russian Federation, 2020). All that suggests that the Russian government deliberately attaches great importance to the development and implementation of the targeted 
program of international influence of Russian higher education on the international market in recruiting and training foreign specialists.

In light of the review, the adjustment and intercultural change system of remote understudies' instructive procedure in Russian colleges with regards to globalization and Eurasian joining of socio-social and instructive space has not been considered. Thus, the aim of this paper is to give a sociological investigation of the circumstance identified with instructive procedure and association of outside understudies in Russian colleges in appraisals and connections of understudies from China that will assist with recognizing the genuine issues of adjustment to new states of socio-social and instructive space.

\section{REVIEW OF LITERATURE}

Outsider understudies face a huge number of issues, among which are poor social adjustment and school incorporation. Then again, albeit computerized portrayals are broadly utilized in training, they are once in a while utilized for supporting understudies or for the goals of complex issues (Fokides, E. 2016). Examples of Japanese college understudy homeroom conduct that regularly aggravate remote educators, the attributes of Japanese informative style, and the job of the college in Japanese society were inspected (Norris, R. W. 2004).

The education of outside understudies in Jiangsu has made some achievements. However, there are still a few issues: low initiative, backward limited time apparatuses, and content, less disciplinary competitiveness, improper instructing mode (Bu-feng, C. A. O. 2011). An investigation broke down the social change and adapting systems of Timorese, Nepalese and Indians, and Koreans selected at Tarlac State University (TSU) during the school year 2007-09 in Tarlac. The Timorese, Nepalese, and Indians could barely mix with different understudies due to their smell which Filipino understudies discovered hard to take. The Koreans utilized their financial favorable position to make the most of their stay in the nation, while the Timorese would be advised to conditions here than at home (Sicat, R. M. 2011).

An endeavor was done to assist instructors with comprehension and take care of their understudies' social issues in the study hall. Moreover, it analyzed the understudies' thoughts regarding social contrasts (İlter, B. G., \&Güzeller, C. O. 2005). The adjustment issues of outsiders in colleges of Russia, uncover all the battles understudies face each day, and gave approaches to take care of the issues or to make them immaterial were examined (Andamasova, A. B. 2019).

Understudy phonetic information is inalienably associated with the interactional occasion and to the particular social setting. During the logical succession, members guarantee intersubjective comprehension, while the understudy turns into the semantic master and has the chance to impart her mastery to the others (Merke, S. 2016).

the issues looked by the Turkish educators serving in the essential training establishments and camps inside the system of the undertaking PICTES in showing Turkish as an unknown dialect to Syrian understudies and to give bits of knowledge into their assessments on their support in the accreditation program for encouraging Turkish as an unknown dialect made by Turkish Language Teaching, Research and Application Center (TOMER), were resolved (Ozkale, U., \&Yelken, T. Y. 2020). The components encouraging or hindering Vietnamese worldwide understudies' adjustment to France were considered to look into (O'Reilly, A., Ryan, D., \& Hickey, T. 2010).

Examination of distributions of Russian and remote researchers uncovered the accompanying issues: a low degree of physical strength of youngsters entering colleges; lacking coordination base; nonattendance of a brought together evaluation arrangement of understudies' physical wellness; noteworthy contrasts in the educational program. An examination found the best types of sorting out physical instruction instructional meetings considering all these negative components (Osipov, A., Vonog, V., Prokhorova, O., \&Zhavner, T. 2016). Local students on the opposite feel comfortable consequently they don't self-destruct from the typical lifestyle and need to scan for some internal motivation. The mental procedure in association with the social and social condition was depicted (Kazakova, J. K., \& Shastina, E. M. 2019).

\section{MATERIALS AND METHODS}

The fundamental basis of this study is an empirical one - a survey on the topic "Study of Satisfaction with the Organization of Chinese students' life at Russian Universities". $\mathrm{N}=615$, representing Chinese students studying in Russian universities. Representation of sociological information is provided by a multi-stage stratified sample with quota selection of units of observation (respondents) on the last step. The poll results were presented in linear and pairwise distributions. Processing and analysis of the survey results were carried out by methods of mathematical statistics and include statistical procedures to the classification of respondents according to the nature of their responses.

Methodical research apparatus includes methods of statistical and comparative analysis and synthesis.

\section{RESULTS AND DISCUSSION}

\section{The Dynamics of Educational Exchanges between Russia and China}

It should be noted that these dynamics are adequately implemented in the relationship between the educational systems of Russia and China. According to the FGANU «Sociocenter», the number of Chinese students in Russia is growing fast: 
in the 2015-2016 academic year in Russian universities there studied 22 thousand of Chinese students; in 2016-2017 32.529; in 2018-2019 the number of students has reached 76.470. Chinese students can study at 305 universities in 85 cities; the largest number of Chinese students is in Moscow, St. Petersburg, and the Far East. The most popular universities are Lomonosov Moscow State University, Saint Petersburg Polytechnical University, Saint-Petersburg State University, Herzen State Pedagogical University of Russia, and the Peoples’ Friendship University of Russia.

Overall, describing the major trends in the evaluation of possible perspectives they should note that in 2019, compared with the previous year, the number of Chinese students studying in Russia increased by more than $10 \%$. Here there is a stable growth trend, based on the fact that the total number of Chinese students increased by almost two times over the last seven years (Materials of the official site 5-100).

Experts associate the positive dynamics with the implementation of the current Chinese development strategy "One Belt and One Road", in which Russia is seen as a political and economic partner. Thus, the process gets double-sided character: the growing demand of China in the expansion of "new wave" educational training, and strengthening of Russian competitive struggle for the education market, with the participation of foreign students (Luo, 2019). Thus, in the framework of the national "Education" project by the end of 2024, the number of foreign students in Russian universities should be about 425 thousand people. The national "Education" project covers the period from 2019 to 2024 and aims to ensure the global competitiveness of Russian education and entry into the top 10 countries on the quality of general education (Ministry of Science and Higher Education of the Russian Federation, 2020).

At the same time, although today the Russian-Chinese cooperation in the field of education has reached a new level, the number of Chinese students in Russia is still great, but this is much less than the number of Chinese students in Western Europe, USA, and Japan. For example, in the 2017-2018 academic year, in Russia, there were studying nearly 80 thousand Chinese students, which is the second-largest number of foreign students studying in Russia, but only $4 \%$ of the total number of Chinese students studying abroad.

Meanwhile, the general conclusion arising from the analysis of educational exchange dynamics in exploiting the opportunities of Russian and Chinese educational systems demonstrates the growing interest of Chinese students for education in Russian universities. This kind of social trend creates a need for a more comprehensive study of internal and external factors to meet the increasing demand by improving the quality of socio-educational conditions. It is not only a more complete study of the necessary steps to a full consideration of specificities of the living environment, culture, society, and educational process, in which there are large changes (Filimonova\&Romanyuk, 2014) which act on a certain way of life. There is an obvious necessity of studying the motives that operate the choice of education place, the relevance of professional choice, the focus on the ultimate goal of the learning process, and much more.

\section{Sociological Portrait of a Chinese Student in a Russian University}

One of the starting points of the socio-educational appearance of a Chinese student is the original reason for choosing Russia to receive professional education. From this point of view, we can use the existing research materials that will identify some of the features of the social starting point of the Chinese student movement. On this basis, Chinese students' reasons for studying in Russia are the following:

- Favorable geographic location. Russia is close to China, the two countries are land neighbors, and there is convenient transport accessibility (Xu-Juanjuan, 2019).

- Adequate educational resources and a high level of pedagogical culture. In Russia, there are about 3 thousand universities, including such as the Moscow State University and St. Petersburg State University, which occupy an important place in the world. In addition, Russia has trained many prominent people in different fields; such a strong theoretical and methodological basis attracts many young professionals.

- Integration of Russian higher education system and accessibility of higher education. Through participation in the Bologna Process, the Russian diploma is recognized in the European countries and has the same status in the field of academic activities and employment (Liu \& Lin, 2019). At the same time, the sum for professional education in Russia normally ranges from 10 to 17 thousand dollars per year that is generally less than a quarter of European or US education costs. In other words, practically all the families of moderate means can afford to study in Russia. Chinese Scholarship Council gives a great number of chances for a free exchange with Russian universities, even with payment for transportation and accommodation of students.

- Students can apply to Russian universities themselves. If the application, written exam, and certificate of the previous degree is recognized, and there is a basis for invitation from Russia, it gives the right to study in Russian universities. A Russian visa is much easier to get than American or European. As for the Russian language, you can study it at the preparatory faculty.

- State support from Russia. Russian universities desire to accept foreign students and offer a wide range of comfortable educational policies, which is a significant assistance to foreigners in learning and life (Chi, 2019). 


\section{Priority Areas of Training for Chinese Students}

It should be noted that with the increasing number of Chinese students, their choice of profession has also become more diversified. If we analyze the dynamics of specialties choice in recent years, the choice of specialty is mostly focused on Psychology, History, Philology (Linguistics and Translation), Philosophy, Political Science, Journalism, Arts, Sociology, Pedagogy, International Relations, Economics, and Humanities. Although Chinese students have an interest in the promising Russian traditional disciplines like Information Technology, Aerospace Engineering, Nuclear Engineering, and Military Industrial Equipment, such specialties are not yet the subjects of the first choice.

In 2019 the Russian Sociocenter (2019) and the Ministry of Science and Higher Education of the Russian Federation jointly conducted a survey, which showed five groups of the most popular professions among Chinese students studying in Russia (Materials of the official site Sociocenter). In particular, the most popular profession among Chinese students in Russia is the Russian language (Philology) - 31.7\%. The number of Chinese students choosing this specialty has increased in recent years, as in the 2014-2015 academic year there was only $23.8 \%$. In the second place on popularity Economics, Finance, and Management. 22.2\% of the total number of Chinese students chose this specialty. In the third place, there are Humanities and Social specialties (including Political Science, Journalism, etc.): 20\% of Chinese students chose it in 2017 - 2018. Followed by the students who have chosen engineering specialty, we note that proportion has doubled in 12 years: from $7.5 \%$ in the 2005-2006 academic year to $15 \%$ in $2017-2018$. Experts believe that this proportion is still expected to grow in the coming years (Lubava, 2014). In this group of specialties, the most popular are Civil Engineering and Architecture, Mechanical Engineering, Power Engineering, and Transport. Studies also show that in the 2017-2018 academic year 7\% of Chinese students were studying Arts and Culture in Russia, most of them decided to choose Music and Visual Arts.

The analysis involves objective data that allow us to get an idea of some social and educational contours of the processes that mainly determine specifics of formation and trends of Chinese student groups in the socio-educational space of Russian High School. The following is an attempt to analyze the level of personal relationships to characteristics of immediate Chinese student life in the socio-educational space of Russian High School.

The author also conducted a sociological survey among the Chinese students who studied in Russian universities in 2018. The study involved 615 students (233 - male and 64 - female). The questionnaire consisted of 26 questions on a given topic.

One of the most important questions in the questionnaire was associated with a sense of purpose that defines the meaning of the choice of the Russian education system. The answer to this largely determines not only direction but also the degree of educational interest activity. It turned out that $40 \%$ of respondents came to Russia to study and get Russian qualification. About $22 \%$ of Chinese students were focused on finding opportunities for a suitable job; $8 \%$ of the students decided to study for future immigration to Russia. It is interesting to note that more than $30 \%$ of respondents linked their choice with the understanding of the attractiveness of Russian culture and great opportunities for professional development.

The current relations between Russian teachers and Chinese students formed positive relationships in order to overcome the difficulties of learning. However, respondents noted some misunderstanding because of the language barrier and socio-cultural differences, suggesting the need for special training not only for the foreign students but also for the Russian teachers engaged in educational work.

$30.6 \%$ of respondents noted that the faculty contributes to the formation of interest in the educational process. Some Chinese students noted the barriers that prevent them from becoming a part of an effective educational process that is primarily associated with a significant difference in teaching culture and methods of educational process organization. The language is a significant barrier for Chinese students (Zhou, 2017), despite the fact that a considerable part of them is studying at preparatory departments. After enrollment, Chinese students have the optional opportunity to continue their Russian language studies, but the lectures in core subjects have a completely different level of linguistic presentation. $12.3 \%$ of Chinese students generally cannot understand the content of the material.

Russian teachers use interactive and active forms of learning in the educational process (e.g., presentations, round tables, discussions, etc.) that is very different from the way of teaching in China, therefore, Chinese students have great difficulty adapting to these new circumstances (Ning, 2017). The system of evaluation is different as well, in Russian universities, it focuses on the development of the applied abilities and skills of students, but in China, a written exam is the main form of control which has a large share of teaching time.

Apparently, these differences arise because $15.4 \%$ of Chinese students take a precautionary response to the question of recommendations to their friends to study in Russia - they are likely not to recommend it. As for the reasons why Chinese students would not recommend to study in Russia, 38\% chose the natural factor, while $29 \%$ chose cultural factor - that is clear enough. At the same time, $27 \%$ of the students noted the safety factor, therefore, the degree of attraction to study in Russian High Schools is not only a task of universities but also of the society as a whole. 


\section{CONCLUSION}

Today, when China and Russia are strategic partners; there is a need for specialists in the field of communications, commerce, and culture (Luo \&Bolotova, 2019). With the development of the "One Belt and One Road" project and the important cooperation of enterprises between the two countries, the relationships between Russia and China are strengthening with each passing day. To expand the scope of cooperation both countries need multidisciplinary specialists that also place new demands on cooperation in the sphere of higher education of China and Russia. The training of foreign students in China and Russia can be viewed as one of the most important ways of improving and deepening cooperation between the two countries.

Training of foreign students in China and Russia can strengthen the "soft power" of the given countries, by human resources (the most valuable national resource) - to increase the attractiveness and competitiveness of the two countries in the world (Guruleva, 2018). Training of foreign students in China and Russia should fully use international experience and education to develop elite international competitiveness, establish the status of China and Russia as countries of powerful education on the world education market, strengthen the national security of China and Russia, expand the geopolitical space of the two countries, promote the integration and communication of science and culture, ensure stability and quality of scientific and educational institutions of China and Russia.

With the help of foreign students training China and Russia can find, educate and prepare innovative elite intellectual professionals, create a team of high-quality professionals of the future with the ability to support the development of the country and to get a youth research cohort that represents the future of science and techniques in China and Russia.

\section{LIMITATION AND STUDY FORWARD}

This study was conducted only on foreign students in Russia. While this research can be done globally to get more accurate and general results.

\section{ACKNOWLEDGMENTS}

The author confirms that the data do not contain any conflict of interest.

\section{AUTHORS CONTRIBUTION}

Chzhao Dan and Yakov A. Aslanov developed a program, provided sociological research and processed the data obtained using the SPSS program (version 23.0). Mikhail D. Rozin, Valery P. Svechkarev and Vladimir I. Mareev analyzed the results of the conducted sociological research.

\section{REFERENCES}

1. Alvergne, A., \&Lummaa, V. (2010). Does the contraceptive pill alter mate choice in humans? Trends in Ecology \& Evolution, 25(3), 171-179. https://doi.org/10.1016/j.tree.2009.08.003

2. Andamasova, A. B. (2019). ADAPTATION PROBLEMS OF FOREIGN STUDENTS IN RUSSIAN UNIVERSITIES. Современныйученый, (3), 12-14.

3. Baumeister, R. F., \&Muraven, M. (1996). Identity as an adaptation to social, cultural, and historical context. Journal of adolescence, 19(5), 405-416. https://doi.org/10.1006/jado.1996.0039

4. Brewster, C., Suutari, V., \&Haslberger, A. (2005). Facets and dimensions of cross-cultural adaptation: refining the tools. Personnel Review.

5. Bu-feng, C. A. O. (2011). The Number of Foreign Students and Their Education in Jiangsu: the Status Quo and Problems. Journal of Yangzhou University (Higher Education Study Edition), (5), 10.

6. Chi, H. (2019). Chinese-Russian cross-border higher education: status, problems, and reflections. Research and evaluation of education Shanghai, 801, 50-54.

7. Diogo, R. (2004). Morphological Evolution, Adaptations, Homoplasies, Constraints, and Evolutionary Trends: Catfishes as a Case Study on General Phylogeny \& Macroevolution. CRC Press. https://doi.org/10.1201/9781482280081

8. Filimonova, N.Y., and Romanyuk, E.S. (2014). Chinese students in Russian universities. Higher education in Russia, 8(9), 76-81.

9. Fokides, E. (2016). Using autobiographical digital storytelling for the integration of a foreign student in the school environment. A case study. Journal of Information Technology Education: Innovations in Practice, 15(1), 99-115. https://doi.org/10.28945/3526

10. Guruleva, T.L. (2018). Joint educational programs of Russia and China: state and problems of implementation. Higher education in Russia, 12, 93-103. https://doi.org/10.31992/0869-3617-2018-27-12-93-103

11. İlter, B. G., \&Güzeller, C. O. (2005). Cultural problems of Turkish students while learning English as a foreign language. DilDergisi, (127), 54-63.

12. Kazakova, J. K., \&Shastina, E. M. (2019). The impact of socio-cultural differences on the formation of intrinsic motivation: The case of local and foreign students. Learning and Motivation, 65, 1-9. https://doi.org/10.1016/j.lmot.2018.10.001 
13. Liu, Jin, and Lin, M.A. (2019). Research on the current situation and trends in higher education in the countries included in the "one belt and one road" initiative (30) - on the example of Russia. Information on education around the world, 3213, 33-38.

14. Lubava, S. (2014). Studies and countermeasures of the problem of narrow specialty choices of Chinese students studying in Russia. Journal of Mudanjiang pedagogical College (publication on philosophy and Social Sciences), 6, 133-134.

15. Luo, M. (2019). Review of the state of education in Russia and its impact on Chinese students studying in Russia. Modernization of education, 638, 82-83.

16. Luo, W., and Bolotova, E.L. (2019). Problems of implementing joint educational programs in the conditions of cooperation between Russian and Chinese universities. Problems of pedagogical education, 1, 16-21.

17. Merke, S. (2016). Establishing the explainable in Finnish-as-a-foreign-language classroom interaction: Studentinitiated explanation sequences. Learning, Culture, and Social Interaction,9, 1-15. https://doi.org/10.1016/j.lcsi.2016.03.002

18. Miller, S., Leve, L. D., \&Kerig, P. K. (Eds.). (2011). Delinquent girls: Contexts, relationships, and adaptation. Springer Science \& Business Media. https://doi.org/10.1007/978-1-4614-0415-6

19. Ministry of Science and Higher Education of the Russian Federation. (2020). Materials of the official site 5100. https://www.5top100.ru

20. Mitchell, W., \& Singh, K. (1996). Survival of businesses using collaborative relationships to commercialize complex goods. Strategic management journal, 17(3), 169-195. https://doi.org/10.1002/(SICI)10970266(199603)17:3<169::AID-SMJ801>3.0.CO;2-\#

21. Ning, Y. (2017). Comparison of internal differences between Chinese and Russian models of University education. Adult education in China, 11, 57-59.

22. Norris, R. W. (2004). Some thoughts on classroom management problems faced by foreign teachers at Japanese universities. Bulletin of Fukuoka International University, 12, 23-30.

23. O'Reilly, A., Ryan, D., \& Hickey, T. (2010). The psychological well-being and sociocultural adaptation of short-term international students in Ireland. Journal of college student development, 51(5), 584-598. https://doi.org/10.1353/csd.2010.0011

24. Osipov, A., Vonog, V., Prokhorova, O., \&Zhavner, T. (2016). Student learning in physical education in Russia (problems and development perspectives). Journal of Physical Education and Sport, 16, 688.

25. Ozkale, U., \&Yelken, T. Y. (2020). Analysis of problems encountered by instructors teaching Turkish as a foreign language to Syrian children and their opinions on their participation in the certification program for teaching Turkish as a foreign language. Journal of Language and Linguistic Studies, 16(1), 185. https://doi.org/10.17263/jlls.712698

26. Parameswaran, M., \&Whinston, A. B. (2007). Research issues in social computing. Journal of the Association for Information Systems, 8(6), 22. https://doi.org/10.17705/1jais.00132

27. Sicat, R. M. (2011). Foreign students' cultural adjustment and coping strategies. International Proceedings of Economics Development \& Research, 5(2), 338-341.

28. Sociocenter. (2019). Materials of the official site Sociocenter. URL:http://sociocenter.info

29. Xu-Juanjuan, L. (2019). The adaptability of Chinese students in the framework of cross-border cooperation in the field of education between Chinese and Russian border universities - on the example of the Manchurian College. Review of Education, 804, 136-138.

30. Zhang, Y., and Sun, H. (2019). Study of educational policy for foreign students in Russia. Review of Education, 2, 159-162.

31. Zhou, D. (2017). Analysis of the current situation of teaching Russian to students studying in Russia and the basics of learning - on the example of Heihe College. Akiko (in the middle of the year), 6, 120-135. 